\begin{tabular}{|c|l|}
\hline Title & Study of electron transport in hydrocarbon gases \\
\hline Author(s) & Hasegawa, H.; Date, H. \\
\hline Citation & $\begin{array}{l}\text { Journal of applied physics, 117(13), 133302 } \\
\text { https://doi.org/10.1063/1.4916606 }\end{array}$ \\
\hline Issue Date & 2015-0408 08 \\
\hline Doc URL & http://hdl.handle.net/2115/59228 \\
\hline Rights & $\begin{array}{l}\text { Copyright 2015 A merican Institute of Physics. This article may be downloaded for personal use only. A ny other use } \\
\text { requires prior permission of the author and the A merican Institute of Physics. The following article appeared in J. A ppl. } \\
\text { Phys. 117, 133302 (2015) and may be found at http://doi.org/10.1063/1.4916606. }\end{array}$ \\
\hline Type & article \\
\hline File Information & J A ppl. Phys._117_133302.pdf \\
\hline
\end{tabular}

Instructions for use 


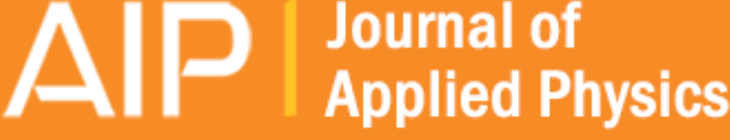

\section{Study of electron transport in hydrocarbon gases}

$\mathrm{H}$. Hasegawa and H. Date

Citation: Journal of Applied Physics 117, 133302 (2015); doi: 10.1063/1.4916606

View online: http://dx.doi.org/10.1063/1.4916606

View Table of Contents: http://scitation.aip.org/content/aip/journal/jap/117/13?ver=pdfcov

Published by the AIP Publishing

\section{Articles you may be interested in}

Measurements of Electron Drift Velocity in Isobutane using the Pulsed Townsend Technique

AIP Conf. Proc. 1351, 212 (2011); 10.1063/1.3608959

Properties of electron swarms in CF 3 I

Appl. Phys. Lett. 95, 101504 (2009); 10.1063/1.3224197

Theoretical investigation of electron transport modulation through benzenedithiol by substituent groups

J. Chem. Phys. 129, 034707 (2008); 10.1063/1.2955463

The Importance of the Metal-Molecule Interface for Charge Transport: A Theoretical and Experimental Study AIP Conf. Proc. 786, 524 (2005); 10.1063/1.2103923

Low temperature electronic transport and electron transfer through organic macromolecules

J. Chem. Phys. 118, 4 (2003); 10.1063/1.1533077

Frustrated by

old technology?

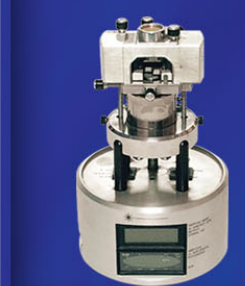

Is your AFM dead

and can't be repaired?

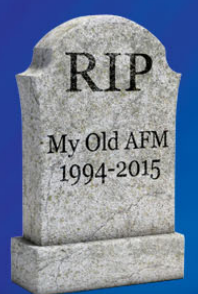

Sick of bad

customer support?

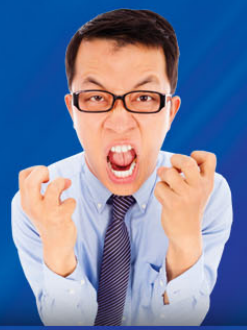

It is time to upgrade your AFM Minimum $\$ 20,000$ trade-in discount for purchases before August 31st

Asylum Research is today's technology leader in AFM

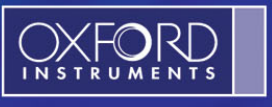




\title{
Study of electron transport in hydrocarbon gases
}

\author{
H. Hasegawa ${ }^{1}$ and H. Date ${ }^{2}$ \\ ${ }^{1}$ Tomakomai National College of Technology, Tomakomai 059-1275, Japan \\ ${ }^{2}$ Faculty of Health Sciences, Hokkaido University, Sapporo 060-0812, Japan
}

(Received 22 November 2014; accepted 20 March 2015; published online 2 April 2015)

\begin{abstract}
The drift velocity and the effective ionization coefficient of electrons in the organic gases, $\mathrm{C}_{2} \mathrm{H}_{2}$, $\mathrm{C}_{2} \mathrm{H}_{4}, \mathrm{C}_{2} \mathrm{H}_{6}, \mathrm{CH}_{3} \mathrm{OH}, \mathrm{C}_{2} \mathrm{H}_{5} \mathrm{OH}, \mathrm{C}_{6} \mathrm{H}_{6}$, and $\mathrm{C}_{6} \mathrm{H}_{5} \mathrm{CH}_{3}$, have been measured over relatively wide ranges of density-reduced electric fields $(\mathrm{E} / \mathrm{N})$ at room temperature (around $300 \mathrm{~K}$ ). The drift velocity was measured, based on the arrival-time spectra of electrons by using a double-shutter drift tube over the $\mathrm{E} / \mathrm{N}$ range from 300 to $2800 \mathrm{Td}$, and the effective ionization coefficient $(\alpha-\eta)$ was determined by the steady-state Townsend method from 150 to $3000 \mathrm{Td}$. Whenever possible, these parameters were compared with those available in the literature. It has been shown that the swarm parameters for these gases have specific tendencies, depending on their molecular configurations. (C) 2015 AIP Publishing LLC. [http://dx.doi.org/10.1063/1.4916606]
\end{abstract}

\section{INTRODUCTION}

The elementary molecules containing carbon and hydrogen atoms (organic molecules) are of importance in manufacturing processes of graphene, carbon nanotubes (CNT), ${ }^{1}$ carbon nanowalls (CNW), ${ }^{2}$ diamond-like carbon (DLC) layers, ${ }^{3}$ and so on. In such processes, the molecules in the gas phase are often made available in the formation and growth of these structures through intermediate plasma states. For the application of a variety of molecules, however, there still remain some data associated with electron collisions to be measured in order to supply fundamental parameters needed in designing with simulation models. Unfortunately, quantities such as electron swarm parameters have seldom been measured in some of these gases over the past few decades.

In this article, we present the experimental results on the electron transport parameters (swarm parameters) for the organic molecules, $\mathrm{C}_{2} \mathrm{H}_{2}$ (acetylene), $\mathrm{C}_{2} \mathrm{H}_{4}$ (ethylene), $\mathrm{C}_{2} \mathrm{H}_{6}$ (ethane), $\mathrm{CH}_{3} \mathrm{OH}$ (methanol), $\mathrm{C}_{2} \mathrm{H}_{5} \mathrm{OH}$ (ethanol), $\mathrm{C}_{6} \mathrm{H}_{6}$ (benzene), and $\mathrm{C}_{6} \mathrm{H}_{5} \mathrm{CH}_{3}$ (toluene), obtained from the arrival-time spectra (ATS) method using a double-shutter drift tube and a steady-state Townsend (SST) method. The experimental swarm parameters for these gases have been scarcely reported so far. Using the ATS method, we have measured the drift velocity, $W_{\mathrm{m}}$ (the mean arrival-time drift velocity) over the density-reduced electric field $\mathrm{E} / \mathrm{N}$ from 300 to $2800 \mathrm{Td}$, while the effective ionization coefficient $\bar{\alpha}$ has been determined with the SST method for E/N values from 150 to $3000 \mathrm{Td}$. Here, $\bar{\alpha}=\alpha-\eta$, where $\alpha$ and $\eta$ are the electron impact ionization and attachment coefficients, respectively. Although these parameters have been herein determined under simplified conditions (i.e., the drift velocity is deduced based on the spatial integration of an electron swarm while the effective ionization coefficient is measured under conditions of the steady-state equilibrium in the uniform electric field), these are the macroscopic quantities to describe the physical aspects accounting for the activity of electrons, particularly those involved ionizing reactions.

Through comparisons of the measured swarm coefficients among the gases, it is shown that these have specific tendencies, which depend on their molecular structures (e.g., normal chain or circularity types and the presence or absence of methyl or hydroxyl in the molecules). Some of the data have been measured for the first time, to our knowledge. It is important to remark that these basic characteristics of electron transport are very useful in a variety of discharge applications with these gases.

\section{EXPERIMENTAL METHOD}

\section{A. Arrival-time spectra method}

The measurement of the drift velocity was performed based on the ATS method ${ }^{4}$ for evaluating the drift velocity $W_{\mathrm{m}}$, which is defined from the ATS of electrons as

$$
W_{m}=\frac{d\langle t\rangle}{d z} .
$$

Here, $\langle t\rangle$ represents the average of the arrival-time of electrons at a position $z$ in the drift tube. The experiment is conducted using a double-shutter drift tube, in which the arriving electrons are collected by the electrode (with shutter-2) at a certain distance from the cathode (with shutter-1) to release initial electrons. ${ }^{4}$ The drift velocity, $W_{\mathrm{m}}$, is deduced by dividing the mean time of arrival of electrons by the distance between the electrodes. The experimental apparatus and procedure for the ATS method were the same as those described by Hasegawa et al. ${ }^{5}$ In the present study, the position of the collector plate was set at four locations, and the final value of drift velocity was determined by averaging the values determined at the four cases for each value of $\mathrm{E} / \mathrm{N}$.

\section{B. Steady-state Townsend method}

The effective ionization coefficient $\bar{\alpha}$ is given by

$$
\begin{gathered}
\bar{\alpha}=\frac{1}{N(z)} \frac{d N(z)}{d z} \\
\text { with } \quad N(z)=\int_{0}^{\infty} n(z, t) d t
\end{gathered}
$$


where $n(z, t)$ is the electron number density at a position $z$ and time $t$. Under the SST conditions, the electron current growth, $I$, is given by

$$
I=I_{0} \frac{\frac{\alpha}{\alpha-\eta} \exp \{(\alpha-\eta) d\}-\frac{\eta}{\alpha-\eta}}{1-\gamma_{T} \frac{\alpha}{\alpha-\eta}[\exp \{(\alpha-\eta) d\}-1]},
$$

where $d$ is the gap spacing between the electrodes, $I_{0}$ is the initial current value, and $\gamma_{\mathrm{T}}$ is the secondary coefficient, respectively. To obtain the effective ionization coefficient, we used the SST method since it provides a more precise value of this coefficient than that obtained by the ATS method.

In the experiment for the organic gases in this study, electron attachment is significant, while the secondary coefficient $\gamma_{\mathrm{T}}$ was found to be negligible. Thus, Eq. (4) readily reduces to

$$
I=I_{0}\left[\frac{\alpha}{\alpha-\eta} \exp \{(\alpha-\eta) d\}-\frac{\eta}{\alpha-\eta}\right] .
$$

We determined $\alpha$ and $\eta$ by fitting this equation to the relation between the current and the gap length using a linearized least-squares method.

The experimental apparatus and analytical procedures for the SST method are basically same as those given by Hasegawa et al. ${ }^{6,7}$ The current measurement was repeated 12-26 times for each gap length and $\mathrm{E} / \mathrm{N}$, and the effective ionization coefficient was determined by averaging the values from the corresponding current measurements.

\section{Purity of the gases and experimental conditions}

The purity of the gases used and the experimental conditions for the field strength and gas pressure are listed in Table I. The drift length between the cathode and shutter-2 to collect electrons in the ATS experiment was $10-40 \mathrm{~mm}$, and the gap length of the electrodes in the SST experiment (using the Harrison type electrodes) was 2-15 mm. Both experiments were performed at room temperature (295-300 K), except for $\mathrm{C}_{6} \mathrm{H}_{6}$ and $\mathrm{C}_{6} \mathrm{H}_{5} \mathrm{CH}_{3}$, which were performed at about $60^{\circ} \mathrm{C}$.

\section{RESULTS AND DISCUSSION}

Figure 1 shows a comparison of the drift velocities $W_{\mathrm{m}}$ obtained for all gases. Two general tendencies are apparent:

TABLE I. Experimental conditions in this study.

\begin{tabular}{lcccccc}
\hline \hline & & \multicolumn{2}{c}{ Reduced electric field, E/N (Td) } & & \multicolumn{2}{c}{ Pressure (Torr) } \\
\cline { 7 - 8 } \cline { 7 - 8 } Gas & Purity (\%) & ATS & SST & & ATS & SST \\
\hline $\mathrm{C}_{2} \mathrm{H}_{2}$ & 99.99 & $300-2500$ & $140-3000$ & & $0.1-0.8$ & $0.2-17$ \\
$\mathrm{C}_{2} \mathrm{H}_{4}$ & 99.999 & $300-2500$ & $140-3000$ & & $0.1-0.7$ & $0.2-17$ \\
$\mathrm{C}_{2} \mathrm{H}_{6}$ & 99.95 & $300-2500$ & $130-3000$ & & $0.1-0.7$ & $0.2-8.0$ \\
$\mathrm{CH}_{3} \mathrm{OH}$ & 99.8 & $300-2300$ & $150-3000$ & & $0.1-0.8$ & $0.4-9.0$ \\
$\mathrm{C}_{2} \mathrm{H}_{5} \mathrm{OH}$ & 99.5 & $300-2500$ & $100-3000$ & & $0.1-0.8$ & $0.4-11$ \\
$\mathrm{C}_{6} \mathrm{H}_{6}$ & 99.7 & $300-2800$ & $100-3000$ & & $0.1-0.6$ & $0.2-22$ \\
$\mathrm{C}_{6} \mathrm{H}_{5} \mathrm{CH}$ & 99.7 & $300-2300$ & $100-3000$ & & $0.1-0.6$ & $0.2-22$ \\
\hline \hline
\end{tabular}

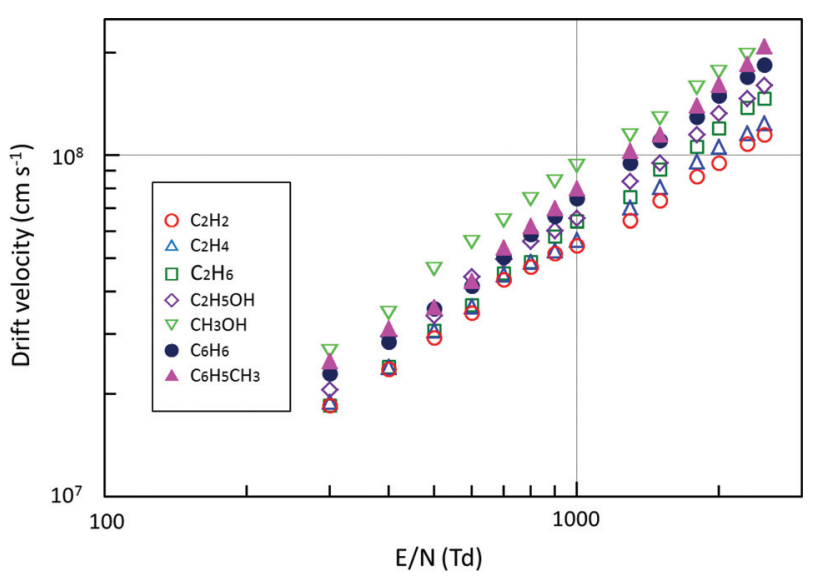

FIG. 1. Comparison of the drift velocity (the mean arrival-time drift velocity, $\left.W_{\mathrm{m}}\right)$.

the value of $W_{\mathrm{m}}$ is smaller as the molecular weight of the gas molecules becomes smaller for the normal chain structure cases of $\mathrm{C}_{2} \mathrm{H}_{2}, \mathrm{C}_{2} \mathrm{H}_{4}$, and $\mathrm{C}_{2} \mathrm{H}_{6}$, while $W_{\mathrm{m}}$ is larger for the gas molecules containing the hydroxyl radical $(-\mathrm{OH})$ than for those without it. Figure 2 shows the drift velocities for $\mathrm{C}_{2} \mathrm{H}_{2}$, $\mathrm{C}_{2} \mathrm{H}_{4}$, and $\mathrm{C}_{2} \mathrm{H}_{6}$ in comparison with the data found in the literatures. ${ }^{8-12}$ Our present results are in good agreement with those from other investigations from 300 to $1000 \mathrm{Td}$. To the best of our knowledge, the drift velocities in these gases for $\mathrm{E} / \mathrm{N}$ above $1000 \mathrm{Td}$ have been measured for the first time in this study.

The density-normalized effective ionization coefficient for all gases under study is shown in Fig. 3. In general, the ionization coefficient for the cyclic molecules, $\mathrm{C}_{6} \mathrm{H}_{6}$ and $\mathrm{C}_{6} \mathrm{H}_{5} \mathrm{CH}_{3}$, is smaller than that for the others, particularly in the low $\mathrm{E} / \mathrm{N}$ region below $500 \mathrm{Td}$. The results are separately shown in Figs. 4-6 for three groups: Fig. 4 for $\mathrm{C}_{2} \mathrm{H}_{2}, \mathrm{C}_{2} \mathrm{H}_{4}$, and $\mathrm{C}_{2} \mathrm{H}_{6}$, Fig. 5 for $\mathrm{CH}_{3} \mathrm{OH}$ and $\mathrm{C}_{2} \mathrm{H}_{5} \mathrm{OH}$, and Fig. 6 for $\mathrm{C}_{6} \mathrm{H}_{6}$ and $\mathrm{C}_{6} \mathrm{H}_{5} \mathrm{CH}_{3}$, and compared with other previously reported data. ${ }^{13-16}$ As in Fig. 4, although there exists a slight difference between our results and other investigations for each gas, the ionization coefficient in $\mathrm{C}_{2} \mathrm{H}_{6}$ is larger than those for the other two molecules over the $\mathrm{E} / \mathrm{N}$ range in this study. As regards $\mathrm{CH}_{3} \mathrm{OH}$, our result is in good agreement

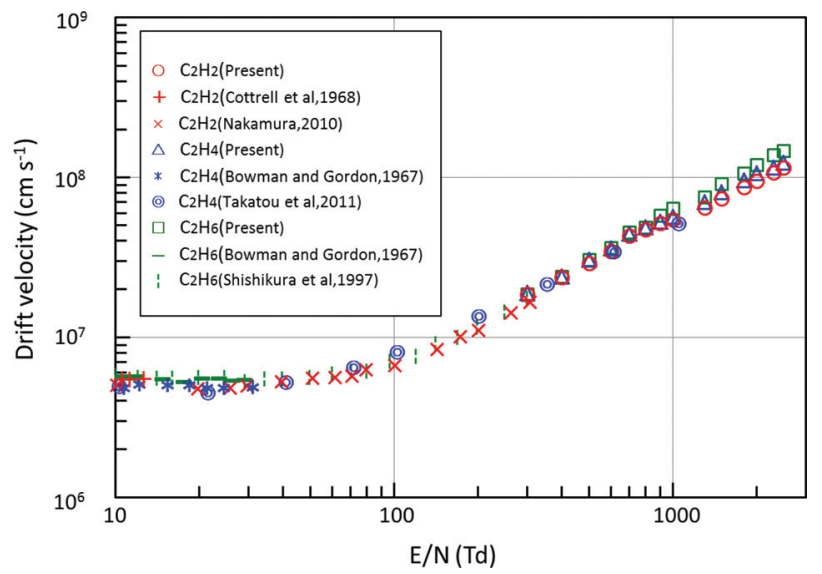

FIG. 2. Drift velocities for $\mathrm{C}_{2} \mathrm{H}_{2}, \mathrm{C}_{2} \mathrm{H}_{4}$, and $\mathrm{C}_{2} \mathrm{H}_{6}$, in comparison with the data from other investigations. Here, the present data are for the mean arrival-time drift velocity $\left(W_{\mathrm{m}}\right)$. 


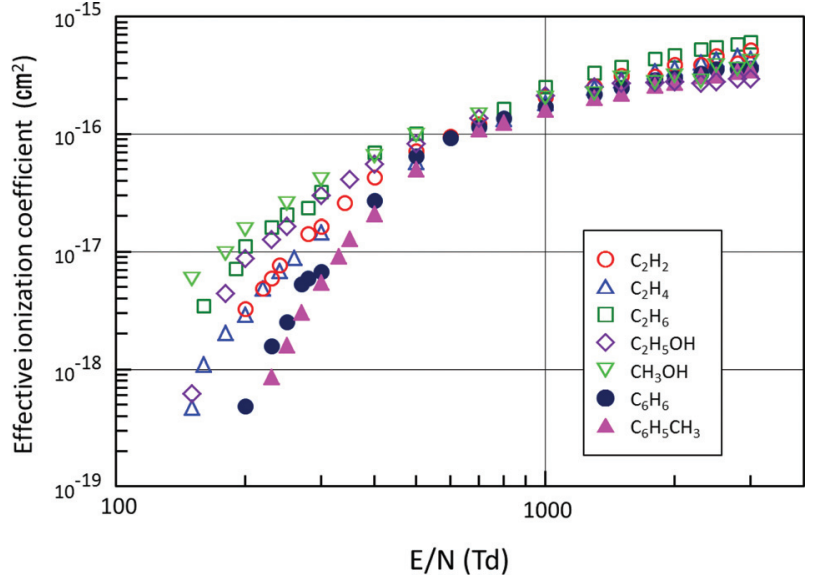

FIG. 3. Comparison of the effective ionization coefficient $(\bar{\alpha} / N=(\alpha-\eta) / N)$.

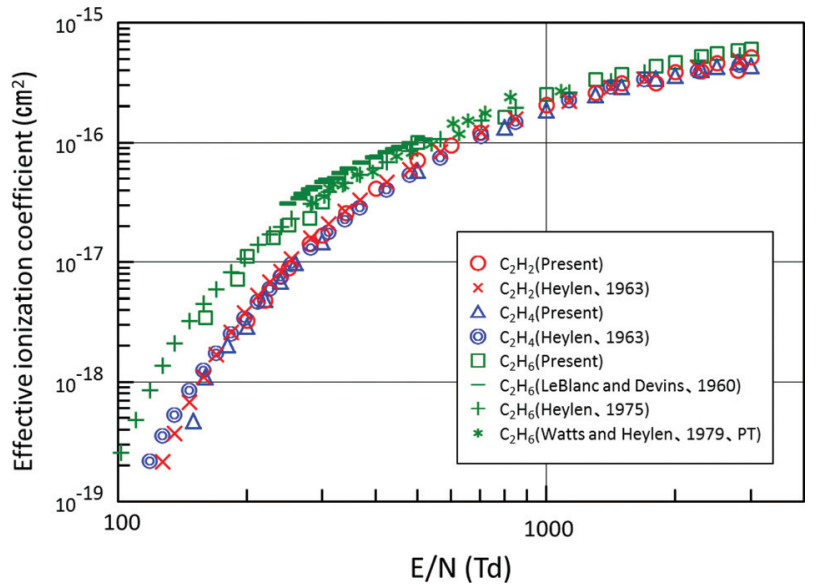

FIG. 4. Effective ionization coefficients $(\bar{\alpha} / N=(\alpha-\eta) / N)$ for $\mathrm{C}_{2} \mathrm{H}_{2}$, $\mathrm{C}_{2} \mathrm{H}_{4}$, and $\mathrm{C}_{2} \mathrm{H}_{6}$, in comparison with the data from other investigations.

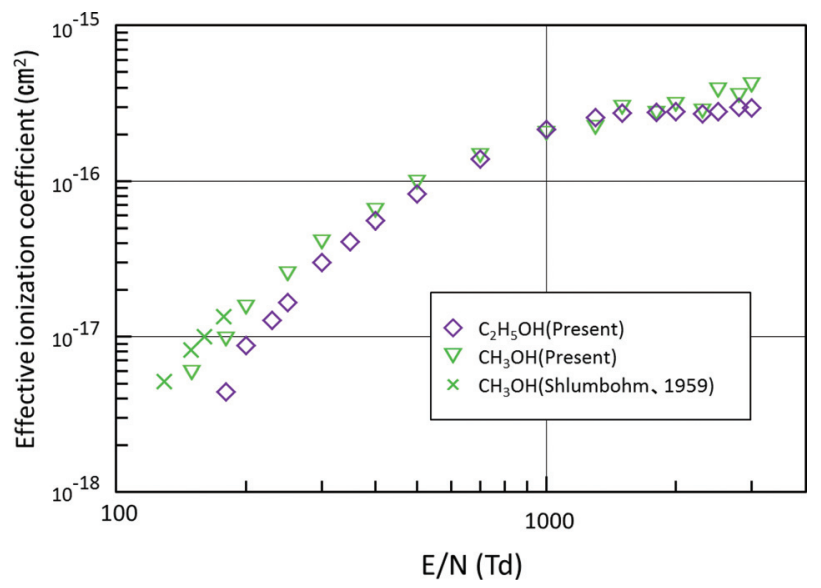

FIG. 5. Effective ionization coefficients $(\bar{\alpha} / N=(\alpha-\eta) / N)$ for $\mathrm{CH}_{3} \mathrm{OH}$ and $\mathrm{C}_{2} \mathrm{H}_{5} \mathrm{OH}$ in comparison with the data by Shlumbohm (1959).

with that of Ref. 17 below $\mathrm{E} / \mathrm{N}=200 \mathrm{Td}$ (see Fig. 5). However, the ionization coefficient for $\mathrm{C}_{6} \mathrm{H}_{6}$ is up to a factor of 2 larger than that of Ref. 18 for $\mathrm{E} / \mathrm{N}$ from 400 to $800 \mathrm{Td}$ as shown in Fig. 6. The ionization coefficients for $\mathrm{C}_{2} \mathrm{H}_{2}$ and

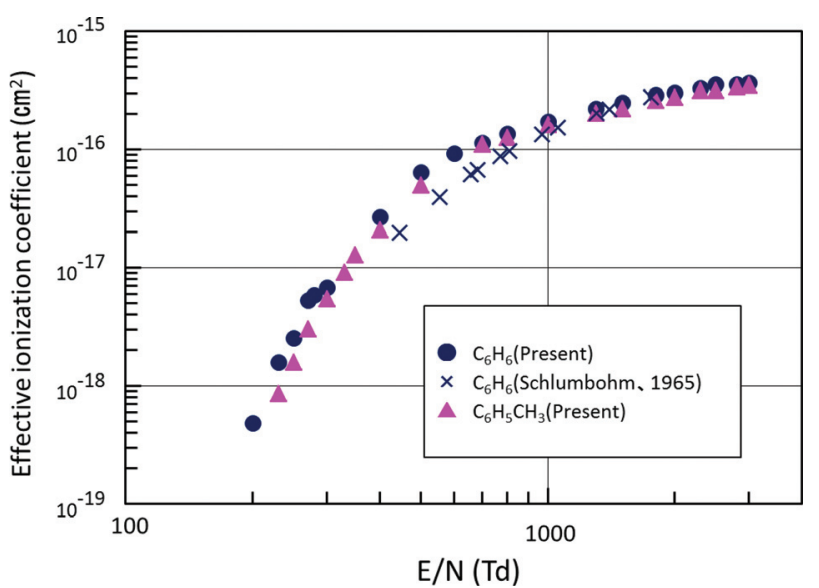

FIG. 6. Effective ionization coefficients $(\bar{\alpha} / N=(\alpha-\eta) / N)$ for $\mathrm{C}_{6} \mathrm{H}_{6}$ in comparison with the data by Shlumbohm (1965) and for $\mathrm{C}_{6} \mathrm{H}_{5} \mathrm{CH}_{3}$.

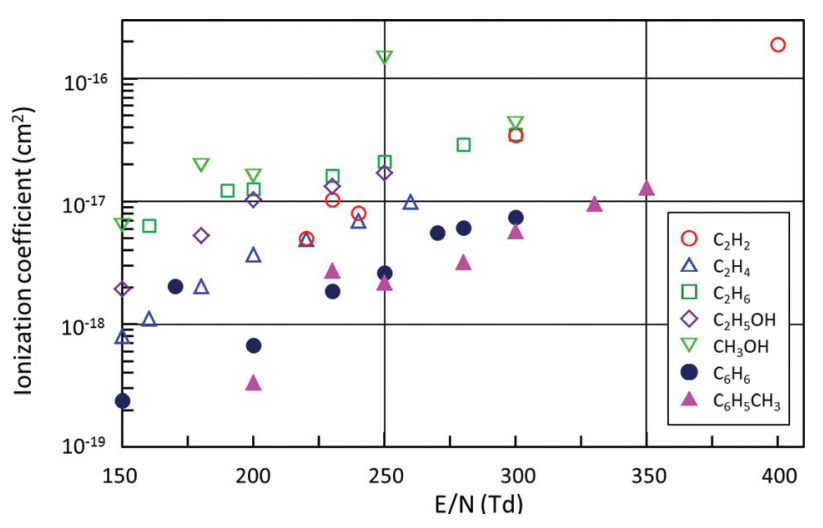

FIG. 7. Comparison of the ionization coefficient $(\alpha / N)$ for the $\mathrm{E} / \mathrm{N}$ range from 150 to $400 \mathrm{Td}$.

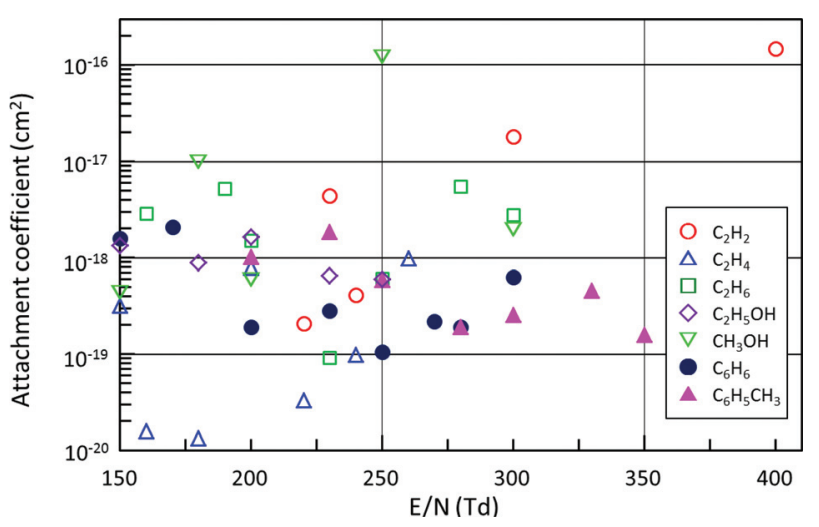

FIG. 8. Comparison of the electron attachment coefficient $(\eta / N)$ for the $\mathrm{E} / \mathrm{N}$ range from 150 to $400 \mathrm{Td}$.

$\mathrm{C}_{2} \mathrm{H}_{4}$ for $\mathrm{E} / \mathrm{N}$ above $2000 \mathrm{Td}, \mathrm{CH}_{3} \mathrm{OH}$ and $\mathrm{C}_{2} \mathrm{H}_{5} \mathrm{OH}$ for $\mathrm{E} / \mathrm{N}$ above $200 \mathrm{Td}$, and $\mathrm{C}_{6} \mathrm{H}_{6}$ for $\mathrm{E} / \mathrm{N}$ above $2000 \mathrm{Td}$ have not been reported previously, and the coefficients in $\mathrm{C}_{6} \mathrm{H}_{5} \mathrm{CH}_{3}$ for $\mathrm{E} / \mathrm{N}$ from 200 to $3000 \mathrm{Td}$ have been measured for the first time. In Figs. 7 and 8, the ionization coefficient $(\alpha / N)$ and the electron attachment coefficient $(\eta / N)$ are plotted separately over a relatively low range of E/N (150-400 Td). As shown in Fig. 8, the resultant values for the attachment 
TABLE II. Ratio of the standard deviation to the mean value.

\begin{tabular}{|c|c|c|c|c|c|c|c|c|c|c|}
\hline \multirow[b]{3}{*}{ Gas } & \multicolumn{4}{|c|}{ ATS } & \multicolumn{6}{|c|}{ SST } \\
\hline & \multicolumn{2}{|c|}{$\sigma / \mathrm{m}(\max )}$. & \multicolumn{2}{|c|}{$\sigma / \mathrm{m}(\min )}$. & \multirow{2}{*}{$\begin{array}{c}\text { Number of positions } \\
\mathrm{N}\end{array}$} & \multicolumn{2}{|c|}{$\sigma / \operatorname{m}(\max )}$. & \multicolumn{2}{|c|}{$\sigma / \mathrm{m}$ (min.) } & \multirow{2}{*}{$\begin{array}{c}\text { Number of current } \\
\text { measurements } \\
n\end{array}$} \\
\hline & $\sigma / \mathrm{m}(\%)$ & $\mathrm{E} / \mathrm{N}(\mathrm{Td})$ & $\sigma / \mathrm{m}(\%)$ & $\mathrm{E} / \mathrm{N}(\mathrm{Td})$ & & $\sigma / \mathrm{m}[\%]$ & $\mathrm{E} / \mathrm{N}(\mathrm{Td})$ & $\sigma / \mathrm{m}(\%)$ & $\mathrm{E} / \mathrm{N}(\mathrm{Td})$ & \\
\hline $\mathrm{C}_{2} \mathrm{H}_{2}$ & 4.01 & 2500 & 0.349 & 500 & 4 & 9.97 & 800 & 1.36 & 2800 & $12-23$ \\
\hline $\mathrm{C}_{2} \mathrm{H}_{4}$ & 3.90 & 2500 & 0.225 & 1300 & 4 & 7.80 & 500 & 0.57 & 800 & $13-23$ \\
\hline $\mathrm{C}_{2} \mathrm{H}_{6}$ & 3.71 & 1800 & 0.182 & 1500 & 4 & 9.51 & 230 & 3.23 & 1000 & $13-23$ \\
\hline $\mathrm{CH}_{3} \mathrm{OH}$ & 5.27 & 1000 & 0.290 & 700 & 4 & 8.90 & 180 & 0.54 & 200 & $14-26$ \\
\hline $\mathrm{C}_{2} \mathrm{H}_{5} \mathrm{OH}$ & 4.79 & 2500 & 0.395 & 900 & 4 & 9.85 & 200 & 0.77 & 500 & $14-23$ \\
\hline $\mathrm{C}_{6} \mathrm{H}_{6}$ & 5.51 & 2300 & 0.192 & 2500 & 4 & 5.53 & 2000 & 1.57 & 700 & $13-23$ \\
\hline $\mathrm{C}_{6} \mathrm{H}_{5} \mathrm{CH} 3$ & 4.16 & 1500 & 0.300 & 700 & 4 & 6.01 & 700 & 0.92 & 2500 & $12-19$ \\
\hline
\end{tabular}

coefficient scatter widely, presumably due to the presence of impurities and for also a statistical reason, and are generally much smaller than the corresponding ionization coefficients over this range of $\mathrm{E} / \mathrm{N}$.

The uncertainty of the values obtained for these coefficients was evaluated by the ratio of $\sigma / \mathrm{m}(\sigma:$ the square of unbiased variance and $\mathrm{m}$ : the average) for the cases of drift distances in the ATS observations and for the iteration of current measurements in the SST method. The maximum and minimum values of $\sigma / \mathrm{m}$ are shown in Table II, where $\mathrm{m}$ and $\sigma$ are defined by

$$
m=\frac{1}{n} \sum_{i=1}^{n} x_{i}
$$

and

$$
\sigma=\sqrt{\frac{1}{n-1} \sum_{i=1}^{n}\left(x_{i}-m\right)^{2}} .
$$

Here, $x_{i}$ represents a measured value and $n$ is the number of values.

The reason why the ionization coefficients in the ring type molecules $\left(\mathrm{C}_{6} \mathrm{H}_{6}\right.$ and $\left.\mathrm{C}_{6} \mathrm{H}_{5} \mathrm{CH}_{3}\right)$ are smaller than those of the chain type molecules as in Fig. 3 may be attributable to the energy transfer from the incident electron to a " $\pi$-electron," absorbing collision energy into the circular configuration, ${ }^{19}$ which in turn decreases the ionization probability of the molecule. With regard to the presence of radical $-\mathrm{OH}$ in the molecules, we can see a major difference between $\mathrm{C}_{2} \mathrm{H}_{5} \mathrm{OH}$ and $\mathrm{C}_{2} \mathrm{H}_{6}$ in Fig. 3, where the ionization coefficient for $\mathrm{C}_{2} \mathrm{H}_{5} \mathrm{OH}$ is much smaller than that for $\mathrm{C}_{2} \mathrm{H}_{6}$ for $\mathrm{E} / \mathrm{N}$ above $1800 \mathrm{Td}$. This may indicate that $-\mathrm{OH}$ acts as a less significant factor than $-\mathrm{H}$ for the ionization process over this $\mathrm{E} / \mathrm{N}$ region by an electron-attracting effect in the molecule. As a matter of fact, the ionization probability and the behavior of electron swarms should be discussed based on the electron collision cross sections. Unfortunately, to our knowledge, the cross section data for $\mathrm{C}_{6} \mathrm{H}_{6}$ and $\mathrm{C}_{6} \mathrm{H}_{5} \mathrm{CH}_{3}$ and for $\mathrm{CH}_{3} \mathrm{OH}$ and $\mathrm{C}_{2} \mathrm{H}_{5} \mathrm{OH}$ are insufficient to explain electron transport parameters in terms of them. However, one feature in Fig. 4 can be interpreted from a view point of the electron collision cross sections, namely, the initial rise of the ionization cross section for $\mathrm{C}_{2} \mathrm{H}_{6}$ at the energy just above the ionization threshold is the largest, while the momentum transfer cross section is the smallest among the three molecules. ${ }^{10,12,20}$

Although the swarm parameters sometimes differ depending on their definitions, particularly at the high E/N region in which the ionization process can occur (e.g., Ref. 4), the exact definition of some parameters and their measurement methods have been established. ${ }^{21}$ Our study presents experimental parameters for the mean arrival-time drift velocity $\left(W_{\mathrm{m}}\right)$ and the Townsend effective ionization coefficient $(\bar{\alpha})$ (including the separate result for the ionization coefficient $\alpha$ and the attachment coefficient $\eta$ over a low range of $\mathrm{E} / \mathrm{N}$ ). The resultant data for the swarm parameters in the organic gases treated here can be used to predict quantitative properties of electron transport in the gases under the action of electric fields.

\section{CONCLUSION}

In this study, the drift velocity $\left(W_{\mathrm{m}}\right)$ of electrons and the effective ionization coefficient $(\alpha-\eta)$ were measured in the organic gases $\left(\mathrm{C}_{2} \mathrm{H}_{2}, \mathrm{C}_{2} \mathrm{H}_{4}, \mathrm{C}_{2} \mathrm{H}_{6}, \mathrm{CH}_{3} \mathrm{OH}, \mathrm{C}_{2} \mathrm{H}_{5} \mathrm{OH}, \mathrm{C}_{6} \mathrm{H}_{6}\right.$, and $\mathrm{C}_{6} \mathrm{H}_{5} \mathrm{CH}_{3}$ ) for relatively wide ranges of $\mathrm{E} / \mathrm{N}$. The drift velocity was obtained by using a double-shutter drift tube and the effective ionization coefficient was determined by the SST method. Some of them were measured for the first time. We recognize that these parameters have specific tendencies, depending on the molecular structure of the gases, such as chain-like or ring-type, and also by the presence or absence of $-\mathrm{OH}$ in the molecule. Some of the results were compared with those in the literature, and good agreement was observed in general. The results in this study on the swarm parameters would be beneficial in a variety of applications of these gases in weakly ionized plasma states.

\section{ACKNOWLEDGMENTS}

The authors are indebted to Y. Okazaki, H. Yokoya, M. Ishizuka, Y. Togashi, and S. Narita for helping us to perform the experiments. This work was supported by JSPS KAKENHI Grant No. 19310033.

${ }^{1}$ M. Kumar and Y. Ando, J. Nanosci. Nanotechnol. 10, 3739-3758 (2010). ${ }^{2}$ K. Teii, S. Shimada, M. Nakashima, and A. T. H. Chuang, J. Appl. Phys. 106, 084303 (2009).

${ }^{3}$ N. Terayama, J. Plasma Fusion Res. 87, 548-555 (2011). 
${ }^{4}$ K. Kondo and H. Tagashira, J. Phys. D: Appl. Phys. 23, 1175-1183 (1990).

${ }^{5}$ H. Hasegawa, H. Date, M. Shimozuma, K. Yoshida, and H. Tagashira, J. Phys. D: Appl. Phys. 29, 2664-2667 (1996).

${ }^{6}$ H. Hasegawa, Y. Sato, K. Murai, M. Shimozuma, and H. Tagashira, J. Phys. D: Appl. Phys. 18, 1361-1370 (1985).

${ }^{7}$ H. Hasegawa, H. Date, and M. Shimozuma, J. Phys. D: Appl. Phys. 40, 2495-2498 (2007).

${ }^{8}$ T. L. Cottrell, W. J. Pollock, and I. C. Walker, Trans. Faraday Soc. 64, 2260-2266 (1968).

${ }^{9}$ J. Takatou, H. Sato, and Y. Nakamura, J. Phys. D: Appl. Phys. 44, 315201 (2011).

${ }^{10}$ Y. Shishikura, K. Asano, and Y. Nakamura, J. Phys. D: Appl. Phys. 30, 1610-1615 (1997).

${ }^{11}$ C. R. Bowman and D. E. Gordon, J. Chem. Phys. 46, 1878-1883 (1967).
${ }^{12}$ Y. Nakamura, J. Phys. D: Appl. Phys. 43, 365201 (2010).

${ }^{13}$ A. E. D. Heylen, J. Chem. Phys. 38, 765-771 (1963).

${ }^{14}$ A. E. D. Heylen, Int. J. Electron. 39, 653-660 (1975).

${ }^{15}$ M. P. Watts and A. E. D. Heylen, J. Phys. D: Appl. Phys. 12, 695-702 (1979).

${ }^{16}$ O. H. LeBlanc and J. C. Devins, Nature 188, 219-220 (1960).

${ }^{17}$ H. Schlumbohm, Z. Angew. Phys. 11, 156-159 (1959).

${ }^{18}$ H. Schlumbohm, Z. Angew. Phys. 139, 492-505 (1965).

${ }^{19}$ J. Clayden, N. Greves, S. Warren, and P. Wothers, Organic Chemistry (Oxford University Press, 2001).

${ }^{20}$ Y. Itikawa, H. Takagi, Y. Nakamura, M. Imai, and A. Sasaki, J. Plasma Fusion Res. 89, 600-610 (2013).

${ }^{21}$ H. Hasegawa, H. Date, K. Yoshida, and M. Shimozuma, J. Appl. Phys. 105, 113308 (2009). 